\title{
Reduction of POME final discharge residual using activated bioadsorbent from oil palm kernel shell
}

\begin{abstract}
A double insulated carbonisation-activation reactor was developed in order to produce activated carbon with high yield and surface area. This reactor was double insulated using low cement castable and covered around the internal space of the reactor with stainless steel plated and fibre glass jacketed heat insulation layer, which allow efficient heat transfer into the bed of material in the reactor. The carbonisation of oil palm kernel shell (OPKS) at $400{ }^{\circ} \mathrm{C}$, followed by steam activation at $500-1000{ }^{\circ} \mathrm{C}$ continuously in the same reactor, with steam flow rate of $12.80-18.17 \mathrm{~L} / \mathrm{min}$ had improved the activated carbon surface area from $305 \pm 10.2 \mathrm{~m} 2 / \mathrm{g}$ to $935 \pm 36.7 \mathrm{~m} 2 / \mathrm{g}$ and gave a high yield of $30 \%$ within $7 \mathrm{~h}$ retention time with a low gaseous emission. The activated carbon produced was successfully applied as bioadsorbent for the treatment of POME final discharge with the reduction of TSS, COD, colour and BOD up to $90 \%, 68 \%, 97 \%$ and $83 \%$, respectively which met the standard set by Department of Environment Malaysia (DOE).
\end{abstract}

Keyword: Carbonisation-activation; Oil palm kernel shell; Activated carbon; Steam; Bioadsorbent 